\title{
Effects of "Shinkeishitsu" on Occupational Stress in Japanese Workers
}

\author{
Shinichi Iwasaki*, Yasuhiko Deguchi and Koki Inoue \\ Department of Neuropsychiatry, Osaka City University, Graduate School of Medicine, Japan
}

Received: March 11, 2014; Accepted: May 07, 2014; Published: May 09, 2014

*Corresponding author: Shinichi Iwasaki, Department of Neuropsychiatry, Osaka City University, Graduate School of Medicine, 1-4-3 Asahimachi Abeno-ku, Osaka City, Osaka 545-8585, Japan, Tel: +81-6-6645-3821; Fax: +81-6-6636-0439; E-mail: siwasaki@med.osaka-cu.ac.jp

\begin{abstract}
The traditional Japanese personality "shinkeishitsu" has become almost outdated even in modern Japanese psychiatry, yet the shinkeishitsu trait can still be found among the Japanese population. Shinkeishitsu relates phobic anxiety disorders, panic disorder, generalized anxiety disorder, obsessive-compulsive disorder, and somatoform disorder. However, the association between workrelated mental problems and shinkeishitsu is still unclear. The purpose of this study was to clarify the effects of shinkeishitsu on occupational stress and depressive symptoms among Japanese workers. This study is based on self-administrated questionnaire applied to 31 Japanese teachers who gave lectures on mental health at school. The shinkeishitsu trait, coping style, depressive symptoms, occupational stress, social support, and a personality-trait subscale were assessed. Shinkeishitsu people were likely to use a type of emotion-oriented coping for stressful situations. Shinkeishitsu had a significant positive correlation with Self-Rating Depression Scale scores. Higher role conflict, role ambiguity, intragroup conflict, and intergroup conflict, as well as lower job control and self-esteem, were associated with higher shinkeishitsu score. The results of this study suggest that the shinkeishitsu trait effects on coping style, role problems and job control, and it is associated with the development of depressive symptoms. Shinkeishitsu is an important personality trait to consider in occupational mental health, even in modern Japan.
\end{abstract}

Keywords: Shinkeishitsu; Demand-control/Support model; Occupational stress; Depressive symptom; Coping style; Japanese workers

\section{Abbreviations}

MDD: Major Depressive Disorder; DC/S: Demand-Control/ Support; CISS: Coping Inventory for Stressful Situations; SDS: Zung's Self-Rating Depression Scale; GJSQ: the Generic Job Stress Questionnaire

\section{Introduction}

\section{Effects of "Shinkeishitsu" on Occupational Stress in Japanese Workers}

According to a 2011 survey by the Ministry of Health, Labour and Welfare, the number of patients in Japan with mental illnesses such as schizophrenia and major depressive disorder (MDD) has increased to over 3.2 million people; in fact, the incidence of
MDD has exceeded that of diabetes (about 2.37 million people) and cancer (about 1.52 million people) [1]. Mental illness is now so prevalent in Japan that it is considered one of the Five Major Diseases in Japanese medicine, and its effects are serious. The survey of completed suicide revealed that mental illness is a particularly important cause of suicide. By 2011, the number of suicides per year in Japan had exceeded 30,000 people [2]. Moreover, there is an increase in the number of various types of workers experiencing mental illness Ministry of Health [1], particularly mood disorders. Therefore, more aggressive efforts should be made to monitor mental health in the Japanese workplace.

Recently, the number of patients with not only MDD, but also MDD with atypical features or adjustment disorders, which are presumed to develop from one's personality, continues to rise among Japanese workers [3,4]. A number of studies have investigated the association between personality traits and job stress. The traditional Japanese personality "shinkeishitsu," which also relates to the Japanese-culture-bound syndrome "taijin-kyofu-sho," has become almost outdated, even in modern Japanese psychiatry [5]. Morita [6] developed a psychiatric classification system and coined the term "shinkeishitsu," or a "nervous trait," to identify a group of related neurotic sufferings and symptoms mediated by certain common psychological, psychosomatic, and somatopsychic processes [7]. Morita shinkeishitsu has three dimensions: symptoms, symptom formation, and character structure. These dimensions include the following: 1) clinical characteristics of the symptoms: ego dystonia of anxiety, adaptation anxiety, defensive oversimplification, self-specialization, symptom-overcoming attitude and problem acknowledgement; 2) symptom formation: psychic interaction and conflicts between the ideal and reality; and 3) character structure: having two symmetric aspects of both "Introversion and Fragility" and "Obsessive and Self-empowering Characteristics" [8]. In addition, an introversiveand fragile aspect must have at least one of these five characteristics: introversion, worrisomeness, interpersonal fragility and hypersensitivity, hypochondriasis, or passivity. In a similar way, anobsessive and self-empowering aspect must have at least one of these five characteristics: desire for perfection, desire for superiority, desire 
for self-esteem, desire for health, or desire for control. Kora [9] differentiated between shinkeishitsu as a trait and shinkeishitsusho (shinkeishitsu disease) as a neurosis. Shinkeishitsu neurosis manifests in various forms, such as phobic obsessions, anxiety, avoidant behaviors, panic attacks, hypochondriasis, and related somatic problems $[10,11]$. Morita [6] indicated that his therapy was specifically designed for treating shinkeishitsu patients. In modern Japanese society, the word "shinkeishitsu" is still a common word, but its meaning represents only nervousness or hysteria. The original meaning of the term "Morita shinkeishitsu" is used as a local diagnosis among Morita therapists, and it remains difficult for people outside this group to understand what Morita shinkeishitsu trulyis [5]. Nevertheless, shinkeishitsu traits can still be found in Japanese workers, as well as in other healthy people. However, there is no study about the association between work-related mental problems and the Morita shinkeishitsu trait, as far as the researchers of the present study are concerned of. Many studies have examined the relationship between personality traits that are similar to shinkeishitsu and problems in the workplace. The Type A personality Friedman [12] is characterized as a person who is ambitious, rigidly organized, highly status-conscious, sensitive, truthful, impatient, always trying to help others, who takes on more than they can handle and wants other people to get to the point, and is also proactive and obsessed with time management. This personality type has been associated with burnout $[13,14]$.

In contrast, the Japanese economic depression is so severe that employees are inundated with many more job tasks than before, and guiding the research on this topic is the job demand-control/support (DC/S) model of occupational stress, a major paradigm of contemporary work-stress research and intervention [15-17]. The model makes explicit the links between psychosocial work conditions and the health and productivity of workers [18]. Karasek [16] has suggested that high job demand without autonomy is more important in predicting depressive symptoms than job demand by itself. In a study by Billings and Moos [19], the correlations of depressive symptoms with work involvement and poor support from superiors and co-workers were somewhat greater than the correlation between depressive symptoms and work pressure, although all the correlations were significant. These findings suggest that stressors related to the job role or content and poor human relations at the workplace, rather than job overload, are key risk factors for depressive symptoms in industrial workers [20]. DC/S model is the most widely used theoretical framework that relates the characteristics of a job to health and well-being, e.g. about teachers [21].

Therefore, we posit an association between depressive symptoms and shinkeishitsu in the workplace. The purpose of this study was to clarify the effects of shinkeishitsu on workers and their depressive symptoms by conducting an investigation on coping style, job demand, job control, and social support along the DC/S model.

\section{Subjects and Methods}

\section{Subjects}

From 2011-2013, teachers who gave lectures on mental health at school were invited to participate in the current study. We distributed questionnaires to 40 teachers agreed to our study who ranged from 23-61 years of age, and of these, 31 completed the questionnaire and participated. Informed consent was obtained from all participants. This was a self-administered questionnaire survey, and demographic factors including age, marital status, and sex were assessed before the psychometric tests below were completed.

The protocol of this study was approved by the Human Subjects Review Committee at Osaka City University (authorization number: 1782).

\section{Participants}

The all sampleswere $(N=31)$ teachers. The mean age was 39.8 $(S D=12.8), 35.5 \%$ were malesand $64.5 \%$ were females. The mean age for males was $43.8(S D=13.2)$. The mean age for females was $37.6(S D=12.4)$. Any demographic factors did not have any significant differences between sexes by t-tests.

\section{Measures of "shinkeishitsu"}

"Shinkeishitsu" was assessed by a self-administered questionnaire for assessing shinkeishitsu trait [8]. This Japaneselanguage questionnaire consists of 25 yes/no items. Table 1 shows each item translated into English. The items were rated on yes $=1$, no $=0$. The total number of "yes" responses forms the shinkeishitsu score. The cut-off point was set at 15 points; a score greater than 15 points was indicative of a shinkeishitsu tendency $(+)$, whereas a score of less than 15 points was classified as shinkeishitsu (-). Great shinkeishitsu tendency (+) is considered to have the same mechanism of symptom formation, which is called "toraware". This means "to be bound as by some intense preoccupation" [22]. Cronbach's alpha for the current study was $0.90(M=8.87, S D=5.89)$.

\section{Coping Inventory for Stressful Situations (CISS) [23]}

The Japanese version of CISS Furukawa [24] consists of 48 items, with 16 items tapping each of the three behavioral categories, and each item has a five-scale Likert-type question ranging from (1) "Not at all” to (5)"Very much". The scores for each category are totalled into a score of 16-80. A higher score indicates that the behavior in question is more common. This instrument measures three types of coping mechanisms: task, avoidance-, and emotion-oriented strategies. Task-oriented coping strategies involve behavioral and cognitive responses that are directed at dealing with the specific problem at hand. Example items include "Schedule my time better." and "Focus on the problem and see how I can solve it". Avoidance-oriented coping strategies are characterized by attempts to avoid distressing situations and can be either person-directed (i.e., seeking out other people) or task-directed (i.e., becoming involved in another task). Example items include "Think about the good times I've had." and "Try to go to sleep". Emotion-oriented coping strategies focus on the individual and aim to manage the distressing feelings that arise from stressful situations. Example items include "Feel anxious about not being able to cope." and "Become very upset". Cronbach's alpha of the task-, avoidance-,emotion-,oriented 
Table 1: Items from "Self-administered questionnaires for shinkeishitsu" by Kitanishi [8], translated by author.

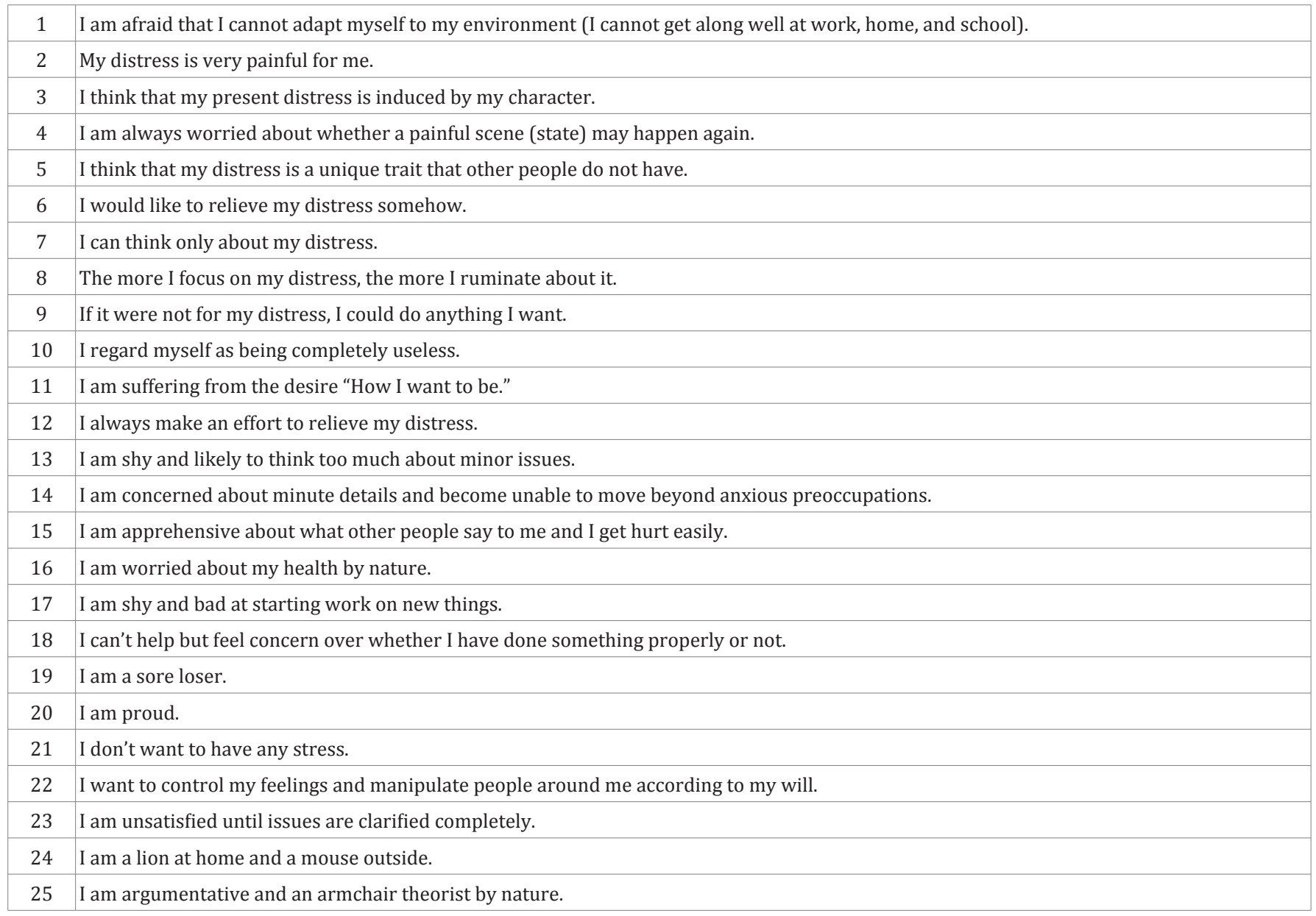

strategies scores for the current study was $0.89,0.84$, and 0.88 $(M=47.3,51.5$, and $53.7, S D=9.7,9.7$, and 11.5).

\section{Zung's Self-Rating Depression Scale (SDS) [25]}

The Japanese version of SDS Fukuda [26] was used to evaluate depressive symptoms. Subjects respond to items such as "I feel down-hearted and blue".Items were rated on a 4-pint Likerttype scale $(0=$ None or a little of the time; $3=$ Most of the time $)$. The responses to the 20 items are then totalled into a possible score of $0-60$. Cronbach's alpha for the current study was 0.91 $(M=22.5, S D=11.6)$.

\section{Generic Job Stress Questionnaire (GJSQ) [27]}

Along with the demographic and occupational variables, we assessed occupational stress using the Japanese version of the Generic Job Stress Questionnaire (GJSQ) Hurreell [27], which has been shown to have sufficient reliability and validity $[28,29]$. The GJSQ is a useful questionnaire for assessing various aspects of occupational stress, including occupational stress and stress reactions at the group and individual level. The original authors of the GJSQ permit the use of the measure's independent subscales for assessing depressive symptoms and occupational stress. Thus, we used six subscales to assess occupational stress;(1) role conflict ( $\mathrm{a}=0.89,8$ items), (2) role ambiguity
( $a=0.79,6$ items), (3) intragroup conflict ( $a=0.90,8$ items), (4) intergroup conflict ( $a=0.67,8$ items), (5) job control $(a=0.92,16$ items), and (6) quantitative workload ( $\mathrm{a}=0.84,11$ items), three social support subscales; (1) social support from one's superior ( $a=0.89,4$ items), (2) from co-workers ( $a=0.81,4$ items), (3) from family or friends $(a=0.86,4$ items)as buffer factors, and a personality characteristic subscale; self-esteem $(a=0.90,10$ items). In general, higher scores for the occupational stress subscales, except for that of job control, indicate greater stress. In contrast, higher scores for job control and the social support subscales indicate lower stress.

\section{Data analysis}

All data were analyzed using the Statistical Package for the Social Sciences, version 21.0 (SPSS 21, IBM USA).

Independent t-tests were used to examine differences in subject characteristics, CISS subscale scores, SDS score, and GJSQ subscales by sexorshinkeishitsu (+) / (-). We also calculated Pearson's $r$ to examine the correlation between SDS, CISS subscales, and GJSQ subscales scores and shinkeishitsu scores.

\section{Results}

Table 2 shows scores of shinkeishitsu scale, SDS, CISS 
subscales and sex differences. Any items did not have any significant differences between sexes by t-test.

CISS scores are shown in Figure 1. The emotion-oriented scores were significantly higher in shinkeishitsu (+) subjects $(M=57.1, S D=9.2)$ than in shinkeishitsu $(-)$ subjects $(M=37.2$, $S D=6.8)$, according to t-test, $\mathrm{t}(29)=6.53, p<0.001$. The $95 \%$ confidence interval of the difference was 13.7 to 26.2 points. The scores for other types of coping did not change according to shinkeishitsu level significantly.

SDS scores in shinkeishitsu (+) group and (-) group are shown in Figure 2. Teachers with shinkeishitsu(+)reported significantly higher depressive scores $(M=38.3, S D=9.5)$ than teachers with shinkeishitsu $(-)(M=17.1, S D=6.0)$, according to t-test, $\mathrm{t}(29)=$ $7.53, p<0.001$. The $95 \%$ confidence interval of the difference was 15.4 to 27.0 points.

Table 3 shows GJSQ subscale scores and the differences between shinkeishitsu (+) and (-) group. In shinkeishitsu (+), role conflict, role ambiguity, intragroup conflict, intergroup conflict scores were significantly higher than scores in shinkeishitsu (-). Job control, social support from coworkers, and self-esteem

Table 2: Means and standard deviations of the subjects.

Notes; SDS: Zung's Self-Rating Depression Scale. CISS: Coping Inventory for Stressful Situations. Data are presented as mean \pm standard deviation.

\begin{tabular}{|c|c|c|c|}
\hline & Total (N=31) & Male (N=11) & Female (N=20) \\
\hline Shinkeishitsu (+) & $\begin{array}{c}17.4 \pm 1.2 \\
(\mathrm{~N}=23)\end{array}$ & $\begin{array}{c}18.3 \pm 0.5 \\
(\mathrm{~N}=4)\end{array}$ & $\begin{array}{c}16.5 \pm 1.0 \\
(\mathrm{~N}=4)\end{array}$ \\
\hline Shinkeishitsu (-) & $\begin{array}{c}5.9 \pm 3.4 \\
(\mathrm{~N}=8)\end{array}$ & $\begin{array}{c}6.0 \pm 3.2 \\
(\mathrm{~N}=7)\end{array}$ & $\begin{array}{c}5.9 \pm 3.6 \\
(\mathrm{~N}=16)\end{array}$ \\
\hline SDS score & $22.5 \pm 11.6$ & $24.2 \pm 11.5$ & $21.6 \pm 11.8$ \\
\hline CISS score: & & & \\
\hline Task-Oriented & $47.3 \pm 9.7$ & $48.8 \pm 10.4$ & $46.4 \pm 9.4$ \\
\hline Avoidant-Oriented & $51.5 \pm 9.6$ & $54.5 \pm 12.6$ & $49.9 \pm 7.5$ \\
\hline Emotion-Oriented & $53.7 \pm 11.5$ & $52.2 \pm 13.8$ & $54.5 \pm 10.3$ \\
\hline
\end{tabular}

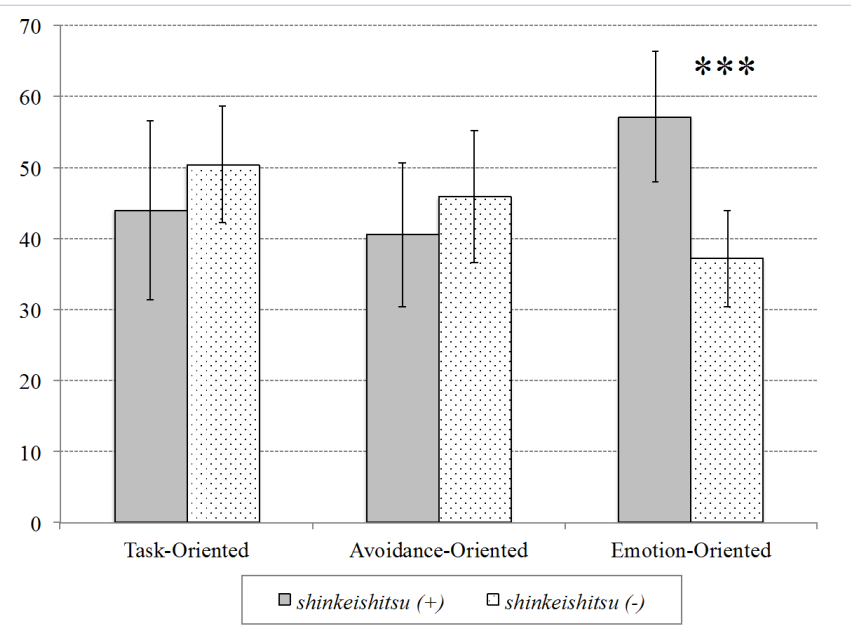

Figure 1: T-test of shinkeishitsu (+) (-) on task, avoidance and emotion oriented coping strategies.

Note: $\mathrm{N}=31^{* * *} \mathrm{p}<0.001$

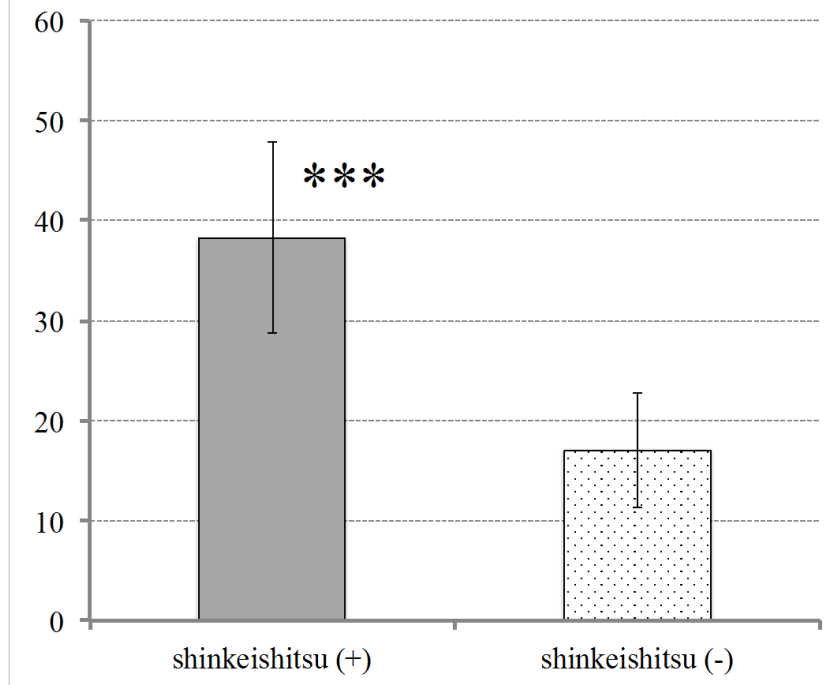

Figure 2: T-test in SDS for shinkeishitsu (+) and (-).

Note: $* * * \mathrm{p}<0.001$

Table 3: Means, standard deviations and t-test between Generic Job Stress Questionnaire (GJSQ) scores with and without shinkeishitsu.

\begin{tabular}{|c|c|c|c|c|c|}
\hline \multirow[b]{2}{*}{$\begin{array}{l}\text { Occupational stress } \\
\text { (range) }\end{array}$} & \multicolumn{2}{|c|}{ Shinkeishitsu(-) } & \multicolumn{2}{|c|}{ Shinkeishitsu(+) } & \multirow[b]{2}{*}{$t$-test } \\
\hline & $\mathbf{M}$ & SD & $\mathbf{M}$ & SD & \\
\hline Role Conflict (8-56) & 28.4 & 7.4 & 42.0 & 7.1 & $-4.53 * * *$ \\
\hline Role Ambiguity (6-42) & 18.2 & 4.5 & 25.0 & 6.2 & $-3.34 * * *$ \\
\hline $\begin{array}{l}\text { Intragroup conflict } \\
(8-40)\end{array}$ & 19.7 & 6.1 & 26.5 & 5.2 & $-2.84 * * *$ \\
\hline $\begin{array}{l}\text { Intergroup conflict } \\
(8-40)\end{array}$ & 17.5 & 4.6 & 25.8 & 4.8 & $-4.30 * * *$ \\
\hline Job control (16-80) & 41.5 & 12.4 & 30.1 & 12.0 & $2.25 *$ \\
\hline $\begin{array}{l}\text { Social support from } \\
\text { superior }(4-20)\end{array}$ & 14.1 & 4.4 & 11.1 & 4.4 & $1.64 \mathrm{~ns}$ \\
\hline $\begin{array}{l}\text { Social support from } \\
\text { coworkers }(4-20)\end{array}$ & 16.5 & 2.7 & 13.6 & 4.0 & $2.28 *$ \\
\hline $\begin{array}{c}\text { Social support from } \\
\text { family/friends (4-20) }\end{array}$ & 16.6 & 3.7 & 14.6 & 3.1 & $1.32 \mathrm{~ns}$ \\
\hline Self-esteem (10-50) & 35.0 & 7.4 & 22.5 & 7.6 & $4.08 * * *$ \\
\hline $\begin{array}{l}\text { Quantitative workload } \\
(11-55)\end{array}$ & 38.3 & 6.7 & 43.9 & 6.9 & $-2.00 \mathrm{~ns}$ \\
\hline
\end{tabular}

${ }^{*} p<0.05,{ }^{* * *} p<0.001, n s=$ not significant

Note: T-test was used for statistical comparison between shinkeishitsu $(+)$ and $(-)$. P values $<0.05$ were considered significant and are denoted by an asterisk in the table.

scores in shinkeishitsu (+) were significantly lower than scores in shinkeishitsu (-).

The correlation between SDS, CISS subscales, and GJSQ subscales scores and shinkeishitsu scores is shown in Table 4. The relationship was investigated using Pearson's $r$. There were strong positive correlations with SDS score, emotion-oriented coping score, role conflict, and intergroup conflict, associated with shinkeishitsu score. There were moderate positive correlations with role ambiguity and intragroup conflict, associated with 
Table 4: Pearson's r correlation coefficients among all study variables in the measures.

\begin{tabular}{|c|c|c|}
\hline & $\mathbf{r}$ & $\mathbf{p}$-value \\
\hline SDS & 0.80 & 0.00 \\
\hline Task-Oriented & -0.43 & $0.02 *$ \\
\hline Avoidance-Oriented & -0.29 & 0.11 \\
\hline Emotion-Oriented & 0.71 & $0.00^{* * *}$ \\
\hline Role Conflict & 0.79 & $0.00^{* * *}$ \\
\hline Role Ambiguity & 0.62 & $0.00 * *$ \\
\hline Intragroup conflict & 0.62 & $0.00^{* * *}$ \\
\hline Intergroup conflict & 0.71 & $0.00^{* * *}$ \\
\hline Job control & -0.33 & 0.07 \\
\hline Social support from superior & -0.40 & $0.03 *$ \\
\hline Social support from coworkers & -0.43 & $0.02 *$ \\
\hline Social support from family/friends & -0.40 & $0.03 *$ \\
\hline Self-esteem & -0.69 & $0.00 * *$ \\
\hline Quantitative workload & 0.32 & 0.08 \\
\hline$* \mathrm{p}<0.05, * * *$ p $<0.001$ & & \\
\hline & & \\
\hline & &
\end{tabular}

shinkeishitsu score. There were moderate negative correlations with task-oriented coping style, three social support, and selfesteem, associated with shinkeishitsu score. Demographic variables (i.e., age, sex, and marital status) did not show any correlations with shinkeishitsu scores and GJSQ subscales scores.

\section{Discussion}

In this study, we examined the association between the shinkeishitsu trait and depressive symptoms, coping styles, and various occupational stressors. Results showed that higher shinkeishitsu scores were associated with higher SDS scores. Additionally, the shinkeishitsu tendency was linked to various occupational stressors. Higher shinkeishitsu tendencies were associated with the utilization of emotion-oriented coping strategies, increased role conflicts, role ambiguity, and intergroup and intragroup conflict, as well as with decreased job control and self-esteem. We hypothesized three pathways from shinkeishitsu to depressive symptoms; (1) coping style, (2) role problems, and (3) job control.

In this study, the increased shinkeishitsu score were correlated withincrease in emotion-oriented coping strongly and decrease in task-oriented coping moderately. Many studies reported the link between the emotion-oriented coping style and psychological problems. Significant associations have been reported between the emotion-oriented coping strategy scale of the CISS and various measures of psychological distress (Endler) [30], personality measures Saklofske [31], leading to nonspecific general psychopathologyin depressive workers Endler [23], depression Billings \& Moos, Barnett \& Gotlib [19,32], and the relapse of depressive episodes [33].On the other hand, the task-oriented coping style is important to work performancein the workplace. The task subscale of the CISS describes purposeful task-oriented efforts aimed at solving problems, cognitively restructuring problems, or altering situations. Such strategies mainly focus on task performance or planning and attempts to solve problems. Some clinical studies have reported that the use of problem-focused and task-oriented coping strategies is associated with a decreased risk of depressive episodes [33]. High emotional-oriented and low task-oriented coping strategies induced by high shinkeishitsu tendency in this study had the similar aspects of developing depressive symptoms to results had reported.

Higher shinkeishitsu tendencies were associated with increased role conflicts and role ambiguity. Some studies reported that role conflicts and role ambiguity are predictors of depressive symptoms. Our previous study showed that teachers' role ambiguity and role conflict increased SDS score [34]. In managerial employees Heinisch [35], workload and role ambiguity that were assessed predicted depressive symptoms. In the other study, role ambiguity predicted subsequent depression in 795 employed adults [36]. A study using a teacher sample found that role conflict predicted emotional exhaustion, i.e., burnout Jackson [37].

In terms of burnout, more neuroticism leads to more job burnout, and of all the Big 5 personality variables, neuroticism has the highest impact on job burnout [38]. Neuroticism, which is one of the Big Five personality traits Costa [39], was associated with job stress and mental diseases. In a Cox's proportional hazard model analysis of the incidence of long-term sick leave because of depressive disorders, higher-level education, higher neuroticism, and having a white-collar job were associated significantly with sick leave because of depressive disorders [40]. Tokuyama [41] reported that the first onset of depression was associated with a past history of neuroticism. Additionally, links between self-esteem and neuroticism have been reported in past research. Rosenberg [42] argued that neurosis was one sign of low self-esteem. In contrast, Eysenck [43] viewed self-esteem as indicative of low neuroticism. Irrespective of the causality between self-esteem and neuroticism, the traits are clearly related [44].

According to the above studies, neuroticism is associated with depressive symptoms and low self-esteem. Shinkeishitsu also had similar effects. Neuroticism and the Type A personality resemble shinkeishitsu to some degree; however, there are many ways in which the two constructs differ from shinkeishitsu. Type A behavior is expressed by three major symptoms: free-floating hostility, time urgency and impatience, and a competitive drive [12]. Neuroticism is expressed as the tendency to experience negative emotions, such as anger, anxiety, or depression, emotional instability, and vulnerability to stress. As described previously, shinkeishitsu has two symmetric aspects of the "introversive and fragile" trait and the "obsessive and selfempowering" trait. Neuroticism is similar to the "introversive and fragile" trait in shinkeishitsu. However, shinkeishitsu also features the opposite trait of "self-empowering" simultaneously, which neuroticism lacks. In Morita Therapy, "desire for life" (i.e., sei-no-yokubo in Japanese, the innate desires to stay alive and to live well) plays a critical role in this "self-empowering" trait [7]. This powerful desire encourages progress toward a goal whereas 
excess desire estranges ideal from reality and provokes strong anxiety. By using this trait, taking corresponding constructive action to lead a fulfilling life is an important therapeutic method in Morita Therapy. The inherent conflict between these two sides of one trait, which differs from the nature of neuroticism, may underlie the characteristics of Japanese workers (i.e., the tendency to be a workaholic or to over-adapt).

According to the DC/S model of occupational stress, shinkeishitsu had an influence on less job control. Inoue et al. [40] reported that low job control might be a strong predictor of longterm sick leave because of depressive disorders. In a review of the evidence, Glass and McKnight concluded the job uncontrollability contributed to negative psychological states largely when there was a discrepancy between career aspirations and occupational achievement. Excess "desire for life" in shinkeishitsu people might also make this discrepancy. A part of shinkeishitsu people has strong "desire for control" as obsessive trait. The difference between their desire for control and reality (job uncontrollability) may contribute to negative psychological states additionally. Shinkeishitsu negatively correlated with three social supports. It is thought that the social support acts as a buffering or moderating variable against the negative consequences of high job strain [45]. The reason for this correlations is unclear, however we speculated how shinkeishitsu made this correlation. Mentioned above, shinkeishitsu has both of the introversive and fragile trait (e.g. interpersonal fragility, hypersensitivity, or passivity) and the obsessive and self-empowering trait (e.g. desire for perfection or desire for superiority).These traits may make them keep the social supports at a distance and lose any social supports (and may also increase group conflict). Shinkeishitsu was not associated with quantitative workload. Because those constructs depend on external factors, shinkeishitsu, which is a personal trait, not be linked. These low job control and low social supports as buffer induced by shinkeishitsu indicates to increase job strain along to JC/S model.

Taken together, shinkeishitsu associated with coping style changes, an increase inrole problems, low job control and social support. We speculate that they mediate or moderate the link between shinkeishitsu and depressive symptoms. Further investigation of the moderating role of job control and social support in the relationship between shinkeishitsu and depressive symptoms is needed.

There are several limitations to this study. First, the sample consisted only of a small, non-clinical group of Japanese teachers. As mentioned above, especially teachers' role conflict and ambiguity tend to induce depressive symptoms. We cannot generalize these teachers' data to a sample of workers with mental health problems. Therefore further studies could include workers from different occupational groupsshould examine whether the shinkeishitsu items are invariable across occupations. In addition, use of Japanese-language scales, as well as other cultural and occupational artifacts in the environment, may have created bias, and in this study, we did not control for these potential confounds. Finally, it is not possible to determine any causal relationship using a cross-sectional study. In the future, including a larger, broader sample can further develop the study of shinkeishitsu in occupational health settings.

\section{Conclusion}

The results of this study suggested that the shinkeishitsu trait effectson coping style, role problems and job control.Itwas associated with the development of depressive symptoms. Shinkeishitsu remains an important personality trait in the study of occupational mental health, even in modern Japan.

\section{References}

1. Ministry of Health Labour and Welfare (2011) Patient Survey Disease and Injury. Ministry of Health Labour and Welfare, Japan.

2. Cabinet Office (2012) White paper on Suicide Prevention in JapanDigestversion. Cabinet Office, Government of Japan.

3. Natsume M (2009) Industrial scenes troubled with adjustment disordershandling and differentiation from depression. Job Stress Research 16(2): 65-71.

4. Tarumi S, Kanba S (2005) The dysthymic type of depression: an essay on sociocultural aspects of depression. Japanese Society for Social Psychiatry 13(3): 129-136.

5. Kitanishi K, Nakamura K, Miyake Y, Hashimoto K, Kubota M (2002) Diagnostic consideration of Morita shinkeishitsu and DSM-III-R. Psychiatry Clin Neurosci 56(6): 603-608.

6. Morita S (1926/1974) The treatment and the true nature of shinkeishitsu and neurasthenia. Hakuyosha, Tokyo, Japan.

7. Ishiyama FI (2003) A bending willow tree: A Japanese (Morita Therapy) model of human nature and client change. Canadian Journal of Counselling 37(3): 216-231.

8. Kitanishi K, Aizawa S, Maruyama S, Hashimoto K (1995) On the diagnostic criteria of Morita Shinkeishitsu. Journal of Morita Therapy 6(1): 15-24.

9. Kora T (1976) Recommendation of Morita Therapy: A method to overcome neurosis. Hakuyosha, Tokyo, Japan.

10. Goto K (1988) Shinkeishitsu treatment by Morita Therapy in its original form. International Bulletin of Morita Therapy 1(2): 37-42.

11. Miura M, Usa S (1970) A psychotherapy of neurosis: Morita therapy. Psychologia 13(1): 18-34.

12. Friedman M (1996) Type A behavior: Its diagnosis and treatment. Plenum Press, New York, USA.

13. Jamal M, Baba V (2001) Type-A behavior job performance and well-being in college teachers. International Journal of Stress Management 8(3): 231240.

14. Nowack KM (1987) Health habits Type A behaviour and job burnout. Work \& Stress 1(2): 135-142.

15. Johnson JV, Hall EM (1988) Job strain work place social support and cardiovascular disease: A cross-sectional study of a random sample of the Swedish working population. Am J Public Health 78(10): 1336-1342.

16. Karasek RA (1979) Job demands job decision latitude and mental strain: Implications for job redesign. Administrative Science Quarterly 24(2): 285-308.

17. Karasek RA, Theorell T (1990) Healthy work: Stress productivity and the reconstruction of working life. Basic Books, New York, USA.

18. Dollard MF, Winefield AH (1998) A test of the Demand-Control/Support 
Model of Work Stress in correctional officers. J Occup Health Psychol 3(3): 243-264.

19. Billings AG, Moos RH (1984) Coping stress and social resources among adults with unipolar depression. J Pers Soc Psychol 46(4): 877-891.

20. Kawakami N, Haratani T, Araki S (1992) Effects of perceived job stress on depressive symptoms in blue-collar workers of an electrical factory in Japan. Scand J Work Environ Health 18(3): 195-200.

21. Cropley M, Dijk DJ, Stanley N (2006) Job strain work rumination and sleep in school teachers. European Journal of Work and Organizational Psychology 15(2): 181-196.

22. Kitanishi K (2001) Psychopathology of egoism. Hakuyosha, Tokyo, Japan.

23. Endler NS (1990) Coping Inventory for Stressful Situations (CISS). MultiHealth Systems, Toronto, Canada.

24. Furukawa T, Suzuki Moor A, Saito Y, Hamanaka T (1993) Reliability and validity of the Japanese version of the coping inventory for stressful situations (CISS): A contribution to the cross-cultural studies of coping. Seishin Shinkeigaku Zasshi 95(8): 602-620.

25. Zung WW (1965) A Self-Rating Depression Scale. Arch Gen Psychiatry 12: $63-70$

26. Fukuda K, Kobayashi S (1973) A study on a self-rating depression scale. Seishin Shinkeigaku Zasshi 75(10): 673-679.

27. Hurrell J, Nelson L, Simmons L (1998) Measuring job stressors and strains: where we have been where we are and where we need to go. J Occup Health Psychol 3(4): 368-389.

28. Haratani T, Kawakami N, Araki S (1993) Reliability and validity of the Japanese version of NIOSH Generic Job Questionnaire. Japanese Journal of Industrial Health 35: 214

29. Haratani T, Kawakami N, Araki S, Hurrell J, Sauter S, et al. (1996) Psychometric properties and stability of the Japanese version of the NIOSH job stress questionnaire. The 25th International Congress on Occupational Health, Stockholm, Sweden: 393.

30. Endler NS, Parker JD, Butcher JN (1993) A factor analytic study of coping styles and the MMPI-2 content scales. J Clin Psychol 49(4): 523-527.

31. Saklofske DH, Kelly IW (1995) Coping and personality. Psychol Rep 77(2): 481-482.

32. Barnett PA, Gotlib IH (1988) Psychosocial functioning and depression: distinguishing among antecedents concomitants and consequences. Psychol Bull 104(1): 97-126.

33. Christensen MV, Kessing LV (2005) Clinical use of coping in affective disorder a critical review of the literature. Clin Pract Epidemiol Ment Health 1(1): 20.

34. Nakao T (2011) Relationships between Depressive Symptoms and Job Stress in School Teachers. Osaka City Medical Journal 60(1-2): 9-16.

35. Heinisch DA, Jex SM (1997) Negative affectivity and gender as moderators of the relationship between work-related stressors and depressed mood at work. Work \& Stress 11(1): 46-57.

36. Fronem MR, Russell M, Cooper ML (1995) Job stressors job involvement and employee health: A test of identity theory. Journal of Occupational and Organizational Psychology 68(1): 1-11.

37. Jackson SE, Schwab RL, Schuler RS (1986) Toward an understanding of the burnout phenomenon. Journal of Applied Psychology 71(4): 630-640.

38. Anvari MRA, Kalali NS, Gholipour A (2011) How does personality affect on job burnout? International Journal of Trade Economics and Finance 2(2): 115-119.

39. Costa PT, McCrae RR (1992) Revised NEO Personality Inventory (NEO PI-R) and NEO Five-Factor Inventory (NEO-FFI). Psychological Assessment Resources, Odessa, Florida, USA.

40. Inoue A, Kawakami N, Haratani T, Kobayashi F, Ishizaki M et al. (2010) Job stressors and long-term sick leave due to depressive disorders among Japanese male employees: Findings from the Japan Work Stress and Health Cohort study. J Epidemiol Community Health 64(3): 229-235.

41. Tokuyama M, Nakao K, Seto M, Watanabe A, Takeda M (2003) Predictors of first-onset major depressive episodes among white-collar workers. Psychiatry Clin Neurosci 57(5): 523-531.

42. Rosenberg M (1965) Society and the adolescent self-image. Princeton University Press, New Jersey, USA.

43. Eysenck HJ (1990) Chapter: Biological dimensions of personality. In: E Pervin (Ed.), Handbook of personality. Guilford Press, New York, USA.

44. Bono JE, Judge TA (2003) Core self-evaluations: A review of the trait and its role in job satisfaction and job performance. Eur. J. Pers 17: 5-18.

45. Cohen S, Wills TA (1985) Stress social support and the buffering hypothesis. Psychol Bull 98(2): 310-357. 